\title{
Serum Levels of High Sensitivity C-reactive Protein in Drug-naïve First-episode Psychosis and Acute Exacerbation of Schizophrenia
}

\author{
Abdullah Bolu, Mehmet Sinan Aydın, Abdullah Akgün, Ali Coşkun, Beyazıt Garip, Taner Öznur, Cemil Çelik, \\ Özcan Uzun \\ Department of Psychiatry, Gülhane Medical Faculty, Health Sciences University, Ankara, Turkey
}

\begin{abstract}
Objective: Findings about inflammatory processes in schizophrenia are increasing day by day. Inflammatory processes in schizophrenia are associated with both its etiology and clinical symptoms. Serum high-sensitivity C-reactive protein (hsCRP) is also one of these inflammatory processes. Particularly, it is thought to be closely related to clinical findings of patients with schizophrenia.

Methods: In this study, the relationship between clinical findings of hsCRP levels of patients with drug-naïve first-episode psychosis (FEP) and patients with schizophrenia in acute exacerbation phase is investigated. Clinical findings, psychometric properties (the Scale for the Assessment of Positive Symptoms, the Scale for the Assessment of Negative Symptoms, Brief Psychiatric Rating Scale), and hsCRP levels of patients were compared.

Results: Forty-eight patients with FEP, 74 patients with schizophrenia in acute exacerbation phase and 54 healthy controlled volunteers are included in the study. The most substantial finding in the study is that there is a positive correlation between hsCRP levels and severity of positive symptoms of both patient groups, with FEP and with schizophrenia. The second most substantial finding is there is no significant difference between patients with FEP and schizophrenia, in terms of hsCRP.

Conclusion: The relationship between hsCRP and positive symptom severity in two groups of patients supports the inflammatory hypothesis in the etiopathogenesis of schizophrenia. This finding is supportive of close relation between inflammatory processes and clinical findings of patient with schizophrenia.
\end{abstract}

KEY WORDS: C-reactive protein; Psychosis; Schizophrenia.

\section{INTRODUCTION}

Schizophrenia is a psychiatric disorder characterized by delusion, hallucination, negative symptoms (social withdrawal and apathy) altered emotional reactivity and disorganized behaviors. ${ }^{1)}$ Schizophrenia is an important public health issue, because its economical burden is huge despite its low prevalence. ${ }^{2)}$ Its etiology is not definitely known yet. One of the important hypotheses to explain its pathogenesis is about immune dysfunction. ${ }^{3)}$ Risk

Received: May 23, 2018 / Revised: July 16, 2018

Accepted: August 16, 2018

Address for correspondence: Mehmet Sinan Aydın, MD

Department of Psychiatry, Gülhane Medical Faculty, Health

Sciences University, Emrah Mahallesi, Gülhane Cd., 06010

Keçiören, Ankara, Turkey

Tel: +90-5065089652, Fax: +90-312-304-4500

E-mail: m.sinan.aydin@hotmail.com

ORCID: https://orcid.org/0000-0002-7218-3972 of contracting schizophrenia for people with high rate of proinflammatory biological markers in plasma and serum is found to be relatively higher. ${ }^{4)}$

C-reactive protein (CRP) is a very commonly used acute phase immune response marker. It is arranged by proinflammatory cytokines. ${ }^{5)}$ It is used in both explaining the pathophysiological factors of inflammatory processes and follow-up of inflammatory diseases. High-sensitivity CRP (hsCRP), on the other hand, is considered the most sensitive test to evaluate CRP levels. $\left.{ }^{6}\right)$ HsCRP is a sensitive marker particularly in cardiovascular risk screening. It is also reported to be closely related with obesity. ${ }^{7)}$ It is also a biological data examined in patients with schizophrenia. $^{2)}$

The hsCRP studies in patients with schizophrenia have been conducted for a couple of reasons. These can be summarized as; studies to associate with metabolic cha-

(ㄷ) This is an Open-Access article distributed under the terms of the Creative Commons Attribution Non-Commercial License (http://creativecommons.org/licenses/by-nc/4.0) which permits unrestricted non-commercial use, distribution, and reproduction in any medium, provided the original work is properly cited. 
nges, ${ }^{8)}$ to be evaluated as a etiological factor within the scope of immune dysfunction hypothesis ${ }^{9)}$ and relation with clinical findings. ${ }^{10)}$

It is reported in a number of studies that hsCRP levels in patients with schizophrenia increased in comparison with control groups. ${ }^{8-14)}$ However, no definite findings have been found on hsCRP in patients with first-episode psychosis (FEP), and also number of studies is not sufficient yet. In this study it is aimed to investigate whether there is a difference between patients with drug-naïve FEP and patient with acute exacerbation of schizophrenia in terms of hsCRP, and also comparing the results with healthy control $(\mathrm{HC})$ group.

\section{METHODS}

\section{Subjects}

The patients conducted in Department of Psychiatry, Gülhane Medical School in Ankara/Turkey. Patients with diagnosis of psychotic attack were randomly selected for the study in between 2017 and 2018. Three groups were formed for the study. The first group consisted of patients with non-effective drug-naïve FEP. Second group consisted of patients with acute exacerbation attack of schizophrenia. And the third group was HC group. The data derived from these patients' blood samples which were drawn at the time of hospitalization, clinical findings and psychometric data were compared. Diagnoses of the patients were made in accordance with the Diagnostic and Statistical Manual of Mental Disorders 5th edition (DSM-5) schizophrenia diagnosis criteria. Severity of the disease was evaluated using Brief Psychiatric Rating Scale (BPRS), the Scale for the Assessment of Negative Symptoms (SANS), the Scale for the Assessment of Positive Symptoms (SAPS) scales. The BPRS was developed by Lukoff et al. ${ }^{15)}$ and was translated into Turkish by Soykan. ${ }^{16)}$ The total score provides information about the severity of the psychotic disorder. It is composed of five subscales: unusual thought content, emotional withdrawal, anxiety-depression, aggression, and agitation. The SANS was developed by Andreasen. ${ }^{17)}$ The Turkish version was reported to be reliable by Erkoc et al. ${ }^{18)}$ This test is comprised of five subscales: affective blunting, alogia, avolition/apathy, anhedonia-asociality, disturbance of attention. The SAPS was developed by Andreasen. ${ }^{17)}$ The Turkish version was reported to be reliable by Erkoc et al. ${ }^{19)}$ This test is com- posed of five subscales: delusions, hallucinations, bizarre behavior, conceptual disorganization, inappropriate affect.

The patients with the first attack who take antipsychotics and patients with affective psychosis were excluded from the study. People with any other chronic medical condition (especially the diseases known to play a role in the etiopathogenesis of the inflammation were investigated diligently) were also excluded. People with any additional psychiatric condition were excluded; also those with mental retardation and those with organic brain damage were not included in the study. For the control group, people with any psychiatric or medical condition were excluded from the study.

\section{Laboratory Procedures}

Venous blood samples of the patients were collected in the day after the hospitalization. General biochemical markers and hsCRP level work-ups of the blood samples were ordered. Venous blood samples from forearm veins of the patients were collected into tubes containing coagulation accelerator thrombin, centrifuged at a rate of $4,000 \mathrm{~g}$ for 5 minutes at $4^{\circ} \mathrm{C}$. Serum samples from patients were collected within 1 hour after admission and between 7 and 9 AM at the day of hospitalization. Serum samples of participants from healthy control group were also collected between 7 and 9 AM Serum hsCRP concentrations were determined by enhanced immunoturbidimetric method. All samples were analyzed by the same analyst, who was blind to the sample sources. The reference range for serum hsCRP is between 0.11 and $3.01 \mathrm{mg} / \mathrm{L}$.

\section{Statistical Analyses}

All data were statistically analyzed using SPSS ver. 15.0 software (SPSS Inc., Chicago, IL, USA). Thanks to Kolmogorov-Smirnov test, hsCRP levels of the patients were found not to be fitting normal distribution. Three groups were compared using Kruskal-Wallis test. Intergroup hsCRP levels were compared between gorups via MannWhitney $U$ test. The demographic variables were compared between groups via the chi-square test for categorical variables. Correlations between variables were assessed with the Spearman correlation coefficient. Parametric tests were used for inter se comparisons of SAPS, SANS, and BPRS measurements of the patients, since they fit normal distribution. The rate was set to $\alpha=0.05$ and $p$ values equal to or lower than this value were considered 
Table 1. Characteristic of groups

\begin{tabular}{lcccl}
\hline \multicolumn{1}{c}{ Characteristic } & FEP $(\mathrm{n}=48)$ & $\mathrm{SZ}(\mathrm{n}=74)$ & $\mathrm{HC}(\mathrm{n}=54)$ & \multicolumn{1}{c}{ Statistics } \\
\hline Smoking & $23(47.9)$ & $38(51.4)$ & $20(37.0)$ & $\chi^{2 *}=2.670, p=0.263$ \\
Age $(\mathrm{yr})$ & $23.5 \pm 3.5$ & $33.1 \pm 13.0$ & $36.3 \pm 12.5$ & $\mathrm{~F}=14.423, p<0.01, \mathrm{SZ}=\mathrm{HC}<\mathrm{FADN}$ \\
Education level $(\mathrm{yr})$ & $9.2 \pm 4.6$ & $8.5 \pm 4.5$ & $9.9 \pm 3.7$ & $\mathrm{~F}=1.287, p=0.279$ \\
BMl $\left(\mathrm{kg} / \mathrm{m}^{2}\right)$ & $27.0 \pm 3.2$ & $27.7 \pm 4.2$ & $26.2 \pm 3.6$ & $\mathrm{~F}=2.656, p=0.073$ \\
Score & & & & \\
SAPS & $50.1 \pm 25.2$ & $33.9 \pm 18.3$ & - & $t=3.062, p=0.003$ \\
SANS & $49.6 \pm 24.3$ & $53.3 \pm 21.8$ & - & $t=0.651, p=0.517$ \\
BPRS & $31.8 \pm 11.1$ & $29.7 \pm 10.2$ & - & $t=0.801, p=0.426$ \\
hSCRP & $3.74 \pm 4.27$ & $5.78 \pm 10.96$ & $1.52 \pm 0.63$ & $\chi^{2^{\dagger}=9.255, p=0.010}$ \\
\hline
\end{tabular}

Values are presented as number (\%) or mean \pm standard deviation. All patients are male.

FEP, first-episode psychosis; SZ, schizophrenia; HC, healthy controls; SAPS, scale for the assessment of positive symptoms; SANS, scale for the assessment of negative symptoms; BPRS, brief psychiatric rating scale; hsCRP, high-sensitivity C-reactive protein.

F value by ANOVA test, t value by Student's $t$ test. ${ }^{*}$ Chi-square test value, ${ }^{\dagger}$ Kruskal-Wallis test value.

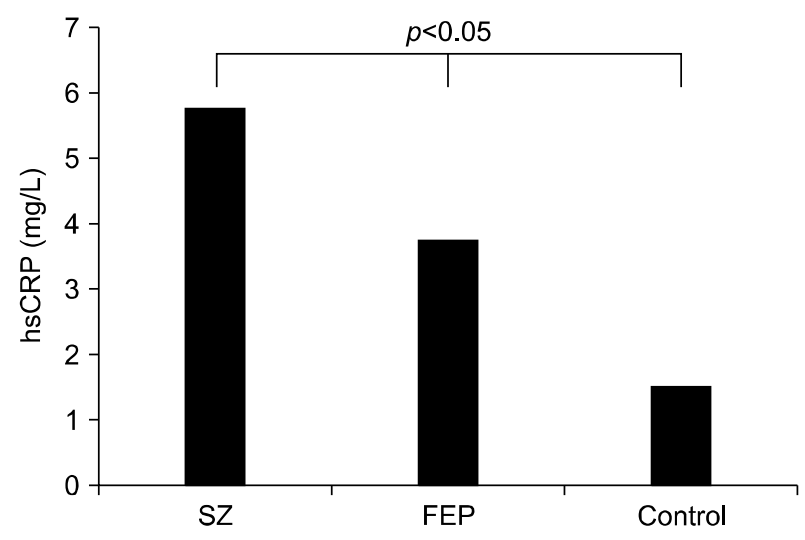

Fig. 1. Comparison of high-sensitvity C-reactive protein (hsCRP) levels in groups.

SZ, schizophrenia; FEP, first-episode psychosis.

statistically significant.

\section{Ethical Considerations}

This study was approved by the Clinical Research Ethics Committee of Numune EAH from Ankara (21.03. 2017-1792). Consent from ethical committee was obtained. Written consent were obtained from patients.

\section{RESULTS}

\section{Clinical and Demographic Characteristics}

The study was concluded with the help of 48 patients with FEP, 74 patients with schizophrenia in acute exacerbation phase and $54 \mathrm{HC}$ volunteers. There was no difference between three groups in terms of age, marital status, education, gender or smoking. The groups were also similar in terms of socio-demographic features (Table 1).

\section{Comparison of Groups' hsCRP Levels}

The hsCRP levels of FEP patients, schizophrenia patients, and $\mathrm{HC}$ group were found to be $3.74 \pm 4.27 \mathrm{mg} / \mathrm{L}$, $5.78 \pm 10.96 \mathrm{mg} / \mathrm{L}$, and $1.52 \pm 0.63 \mathrm{mg} / \mathrm{L}$, respectively. There was statistically significant difference between groups $\left(\chi^{2}=9.255 ; p=0.010\right)$ (Fig. 1$)$. When the groups were compared in pairs; hsCRP levels of patients with FEP were found to be statistically significantly higher than $\mathrm{HC}$ group ( $Z=2.276 ; p=0.023$ ). Also hsCRP levels of patients with schizophrenia were found to be statistically significantly higher than $\mathrm{HC}$ group ( $\mathrm{Z}=2.900 ; p=0.004)$. However, there was no statistically significant difference between patients with FEP and patients with schizophrenia in terms of hsCRP levels $(Z=0.401 ; p=0.688)$.

\section{Comparison of Groups' Clinical Findings}

Comparison of psychometric data of the groups is given in Table 1. SAPS, SANS, and BPRS scores of patients with FEP were found to be $50.4 \pm 25.2,49.7 \pm 24.3$, and $31.8 \pm$ 11.1 , respectively. SAPS, SANS and BPRS scores of patients with schizophrenia were found to be $33.9 \pm 18.3$, $53.4 \pm 21.9$, and $29.7 \pm 10.2$, respectively. There was no statistically significant intergroup difference regarding SANS and BPRS. However there was a significant difference in terms of SAPS scores $(\mathrm{t}=3.047 ; p=0.003)$.

\section{Relation of Groups' hsCRP Levels with Clinical Findings}

The relation between groups' SAPS, SANS and BPRS 
scores and hsCRP levels was studied. Positive correlation between hsCRP levels of patients with FEP and SAPS (rho=0.520, $p=0.002$ ) and BPRS (rho=0.616, $p=0.001$ ) scores was found. Positive correlation between hsCRP levels of patients with schizophrenia and SAPS (rho=0.494, $p=0.004$ ) scores was found.

\section{DISCUSSION}

The most substantial finding in our study is that there is a positive correlation between hsCRP levels and severity of positive symptoms of both patient groups with FEP and with schizophrenia. The second most substantial finding is there is no significant difference between patients with FEP and schizophrenia, in terms of hsCRP. Our study, as far as we are aware of, is one of the rarest studies in which hsCRP levels of patients with schizophrenia during exacerbation and patients with drug naïve FEP were compared.

Immune system dysregulation has a substantial place in the evidences related to etiopathogenesis of schizophrenia. ${ }^{20-22)}$ It is thought to be there is a close relation between autoimmune processes and some subgroups of schizophrenia. ${ }^{23)}$ There are consistent information particularly on proinflammatory processes in schizophrenia. ${ }^{24)}$ Findings of our study are also supportive of this hypothesis.

Researchers reported that hsCRP levels in schizophrenia patients are higher than in the control group.,25) However, findings related to changes in that increased levels of hsCRP through time or through treatment have not been clearly revealed yet. ${ }^{9)}$ It is also reported that no significant difference between first attack psychosis and schizophrenia in terms of CRP. In a current meta-analysis of 26 studies, it is noted that there was no difference in CRP levels of patients with FEP and patients with schizophrenia, and CRP levels were moderately elevated in both groups in general. ${ }^{9)}$ The finding of our study that there is no difference in CRP between patients with FEP and patients with schizophrenia in this study is consistent with general conclusion. Moreover, for patients with schizophrenia being in the state of acute attack seems to affect this result.

While a relation between hsCRP and SAPS scores were found in our study, some of the previous studies reported just the opposite. In previous studies, levels of CRP have also been reported to be associated with psychopathology, ${ }^{23,26)}$ such as negative symptoms ${ }^{27)}$ and cognitive im- pairment. ${ }^{28)}$ Finding a positive relation between CRP and positive symptoms in both patients with FEP and patients with schizophrenia in acute exacerbation phase in our study, brings CRP's effects on acute exacerbation symptoms, such as agitation, behavioral pathologies and delusion, to mind. In a study conducted in 2016, delusional symptoms were found to be significantly high in the group with higher hsCRP level than the group with lower hsCRP level. ${ }^{29)}$ Another study conducted in 2016 showed a close relationship between CRP and behavioral pathologies such as aggression in patients with schizophrenia. ${ }^{30)}$ Both those findings and our findings are suggestive of a relation between CRP and positive symptoms in acute exacerbation phase.

When studies on drug-naïve FEP patients are considered, CRP levels of 30 patients with FEP were evaluated in a study by De Berardis et al. ${ }^{31)}$; a close relation between patients' CRP levels and alexithymia and suicide risk was found in the study. In a study by Fawzi et al. ${ }^{11)}$ was found a close relation between patients' hsCRP levels and negative scores of Positive and Negative Syndrome Scale. Our findings are not consistent with these findings. In our study, a relation is found between hsCRP and positive symptom scales, not negative symptoms. Particularly in a meta-analysis by Fernandes et al. ${ }^{9)}$ it was concluded that elevated CRP levels is related to severity of positive symptoms which in the most prominent feature of schizophrenia. Authors also reported that there was not any difference in first attack and schizophrenia, independently of use of antipsychotics. Also this result is supportive of results of the present study. In conclusion, this study is consistent with the results of meta-analyses, rather than particular studies.

This study has several limitaions. Patients with FEP could be followed for a longer time, for stronger comparison. Levels of other inflammatory markers (such as interleukin 6, tumor necrosis factor $\alpha$ ) could be examined, together with hsCRP levels. There is a close relationship between inflammation and smoking. The absence of packyear smoking data is a limitation.

Consequently, findings of our study are suggestive of relation between positive symptoms and CRP levels of both patients with first-episode schizophrenia and patients with schizophrenia in acute exacerbation phase. These findings are indicative of no relation between CRP level in schizophrenia and drug use, duration of illness, 
being first episode or chronicity.

\section{Acknowledgments}

We would like to thank all of the study participants and staff.

\section{REFERENCES}

1. Porteous D. Genetic causality in schizophrenia and bipolar disorder: out with the old and in with the new. Curr Opin Genet Dev 2008;18:229-234.

2. Singh B, Chaudhuri TK. Role of C-reactive protein in Schizophrenia: an overview. Psychiatry Res 2014;216:277-285.

3. Khandaker GM, Cousins L, Deakin J, Lennox BR, Yolken R, Jones PB. Inflammation and immunity in schizophrenia: implications for pathophysiology and treatment. Lancet Psychiatry 2015;2:258-270.

4. Wium-Andersen MK, Orsted DD, Nordestgaard BG. Elevated C-reactive protein associated with late- and very-late-onset schizophrenia in the general population: a prospective study. Schizophr Bull 2014;40:1117-1127.

5. Pepys MB, Hirschfield GM. C-reactive protein: a critical update. J Clin Invest 2003;111:1805-1812.

6. Ruth MR, Port AM, Shah M, Bourland AC, Istfan NW, Nelson $\mathrm{KP}$, et al. Consuming a hypocaloric high fat low carbohydrate diet for 12 weeks lowers C-reactive protein, and raises serum adiponectin and high density lipoprotein cholesterol in obese subjects. Metabolism 2013;62:1779-1787.

7. Capuron L, Poitou C, Machaux-Tholliez D, Frochot V, Bouillot JL, Basdevant A, et al. Relationship between adiposity, emotional status and eating behaviour in obese women: role of inflammation. Psychol Med 2011;41:1517-1528.

8. Miller BJ, Culpepper N, Rapaport MH. C-reactive protein levels in schizophrenia: a review and meta-analysis. Clin Schizophr Relat Psychoses 2014; 7:223-230.

9. Fernandes BS, Steiner J, Bernstein HG, Dodd S, Pasco JA, Dean OM, et al. C-reactive protein is increased in schizophrenia but is not altered by antipsychotics: meta-analysis and implications. Mol Psychiatry 2016;21:554-564.

10. Akanji AO, Ohaeri JU, Al-Shammri S, Fatania HR. Association of blood levels of C-reactive protein with clinical phenotypes in Arab schizophrenic patients. Psychiatry Res 2009;169: 56-61.

11. Fawzi MH, Fawzi MM, Fawzi MM, Said NS. C-reactive protein serum level in drug-free male Egyptian patients with schizophrenia. Psychiatry Res 2011;190:91-97.

12. Dickerson F, Stallings C, Origoni A, Vaughan C, Khushalani S, Yang $\mathrm{S}$, et al. C-reactive protein is elevated in schizophrenia. Schizophr Res 2013;143:198-202.

13. Joseph J, Depp C, Martin AS, Daly RE, Glorioso DK, Palmer BW, et al. Associations of high sensitivity C-reactive protein levels in schizophrenia and comparison groups. Schizophr Res 2015; 168:456-460.
14. Inoshita $\mathrm{M}$, Numata $\mathrm{S}$, Tajima $\mathrm{A}$, Kinoshita $\mathrm{M}$, Umehara $\mathrm{H}$, Nakataki M, et al. A significant causal association between C-reactive protein levels and schizophrenia. Sci Rep 2016;6:26105.

15. Lukoff $\mathrm{D}$, Nuechhtriein $\mathrm{KH}$, Vertuna J. Brief Psychiatric Rating Scale (BPRS) Version 4.0, Expanded Version. Los Angeles: UCLA Department of Psychiatry and Biobehavirio/ Sciences, West Los Angeles Medical Center;1993.

16. Soykan C. Institutional differences, and case typicality as related to diagnosis system severity, prognosis and treatment (Unpublished). Ankara:Middle East Technical University; 1989. [Master's thesis].

17. Andreasen NC. Methods for assessing positive and negative symptoms1. In: Andreasen NC, editor. Schizophrenia: Positive and negative symptoms and syndromes. Basel: Karger; 1990. p.73-78.

18. Erkoc $S$, Arkonac O, Atakl ${ }_{1} \mathrm{C}$, Ozmen E. Negatif semptomları değerlendirme ö/çeğinin güvenilirliği ve geçerliliği. Düşünen Adam 1991;4:16-19.

19. Erkoc S, Arkonac O, Ataklı C, Ozmen E. Pozitif semptomları değerlendirme ö/çeğinin güvenilirliği ve geçerliliği. Düşünen Adam 1991;4:20-24.

20. Gibney SM, Drexhage HA. Evidence for a dysregulated immune system in the etiology of psychiatric disorders. J Neuroimmune Pharmacol 2013;8:900-920.

21. Smyth AM, Lawrie SM. The neuroimmunology of schizophrenia. Clin Psychopharmacol Neurosci 2013;11:107-117.

22. Venkatasubramanian G, Debnath M. Neuroimmunological aberrations and cerebral asymmetry abnormalities in schizophrenia: select perspectives on pathogenesis. Clin Psychopharmacol Neurosci 2014;12:8-18.

23. Strous RD, Shoenfeld Y. Schizophrenia, autoimmunity and immune system dysregulation: a comprehensive model updated and revisited. I Autoimmune 2006;27:71-80.

24. Potvin S, Stip E, Sepehry AA, Gendron A, Bah R, Kouassi E. Inflammatory cytokine alterations in schizophrenia: a systematic quantitative review. Biol Psychiatry 2008;63:801-808.

25. Zhang Q, Hong W, Li H, Peng F, Wang F, Li N, et al. Increased ratio of high sensitivity $C$-reactive protein to interleukin-10 as a potential peripheral biomarker of schizophrenia and aggression. Int J Psychophysiol 2017;114:9-15.

26. Fan X, Pristach C, Liu EY, Freudenreich O, Henderson DC, Goff DC. Elevated serum levels of C-reactive protein are associated with more severe psychopathology in a subgroup of patients with schizophrenia. Psychiatry Res 2007;149:267-271.

27. Garcia-Rizo C, Fernandez-Egea E, Oliveira C, Justicia A, Bernardo $\mathrm{M}$, Kirkpatrick B. Inflammatory markers in antipsychotic-naive patients with nonaffective psychosis and deficit vs. nondeflcit features. Psychiatry Res 2012;198:212-215.

28. Dickerson F, Stallings C, Origoni A, Vaughan C, Khushalani S, Yolken R. Additive effects of elevated C-reactive protein and exposure to Herpes simplex virus type 1 on cognitive impairment in individuals with schizophrenia. Schizophr Res 2012; 


\section{4:83-88.}

29. Dimitrov DH, Lee S, Yantis J, Honaker C, Braida N, WalssBass C. Elevated serum levels of high-sensitivity C-reactive proteins are associated with severe delusional symptoms in a subgroup of patients with schizophrenia. J Clin Psychiatry 2016;77:131-132.

30. Barzilay R, Lobel T, Krivoy A, Shlosberg D, Weizman A, Katz N. Elevated C-reactive protein levels in schizophrenia in- patients is associated with aggressive behavior. Eur Psychiatry 2016;31:8-12.

31. De Berardis D, Conti CM, Marinp S, Serroni N, Moschetta FS, Carano A, et al. C-reactive protein level and its relationship with suicide risk and alexithymia among newly diagnosed, drug-naive patients with non-affective psychosis. Eur I Inflamm 2013;11:215-221. 